\title{
A scoping review on health economics in neurosurgery for acute spine trauma
}

\author{
Brian C. F. Chan, PhD, ${ }^{1}$ B. Catharine Craven, MD, MSc, FRCPC,1,2 and \\ Julio C. Furlan, MD, LLB, MBA, MSc, PhD, FRCPC ${ }^{1,2}$ \\ ${ }^{1}$ Lyndhurst Centre, Toronto Rehabilitation Institute, University Health Network; and ${ }^{2}$ Department of Medicine, Division of Physical \\ Medicine and Rehabilitation, University of Toronto, Toronto, Ontario, Canada
}

\begin{abstract}
OBJECTIVE Acute spine trauma (AST) has a relatively low incidence, but it often results in substantial individual impairments and societal economic burden resulting from the associated disability. Given the key role of neurosurgeons in the decision-making regarding operative management of individuals with AST, the authors performed a systematic search with scoping synthesis of relevant literature to review current knowledge regarding the economic burden of AST.

METHODS This systematic review with scoping synthesis included original articles reporting cost-effectiveness, costutility, cost-benefit, cost-minimization, cost-comparison, and economic analyses related to surgical management of AST, whereby AST is defined as trauma to the spine that may result in spinal cord injury with motor, sensory, and/or autonomic impairment. The initial literature search was carried out using MEDLINE, EMBASE, CINAHL, CCTR, and PubMed. All original articles captured in the literature search and published from 1946 to September 27, 2017, were included. Search terms used were the following: (cost analysis, cost effectiveness, cost benefit, economic evaluation or economic impact) AND (spine or spinal cord) AND (surgery or surgical).

RESULTS The literature search captured 5770 titles, of which 11 original studies met the inclusion/exclusion criteria. These 11 studies included 4 cost-utility analyses, 5 cost analyses that compared the cost of intervention with a comparator, and 2 studies examining direct costs without a comparator. There are a few potentially cost-saving strategies in the neurosurgical management of individuals with AST, including 1) early surgical spinal cord decompression for acute traumatic cervical spinal cord injury (or traumatic thoracolumbar fractures, traumatic cervical fractures); 2) surgical treatment of the elderly with type-II odontoid fractures, which is more costly but more effective than the nonoperative approach among individuals with age at AST between 65 and 84 years; 3) surgical treatment of traumatic thoracolumbar spine fractures, which is implicated in greater direct costs but lower general-practitioner visit costs, private expenditures, and absenteeism costs than nonsurgical management; and 4) removal of pedicle screws 1-2 years after posterior instrumented fusion for individuals with thoracolumbar burst fractures, which is more cost-effective than retaining the pedicle screws.
\end{abstract}

CONCLUSIONS This scoping synthesis underscores a number of potentially cost-saving opportunities for neurosurgeons when managing patients with AST. There are significant knowledge gaps regarding the potential economic impact of therapeutic choices for AST that are commonly used by neurosurgeons.

https://thejns.org/doi/abs/10.3171/2018.2.FOCUS17778

KEYWORDS spinal cord injury; acute spine trauma; neurotrauma; costs; health economics

A CUTE spine trauma (AST), though relatively uncommon, is associated with substantial impact to individuals due to the associated motor, sensory, and autonomic impairment; associated disability; and reduced lifespan. ${ }^{15,16,18,20,29,30}$ Hospital trauma centers have documented that AST represents between 2\% and 23\% of trauma admissions in the United States and Canada. ${ }^{29,30}$ Although the epidemiology of AST varies by countries, the most common causes of AST are usually motor vehicle accidents, falls, and sports-related trauma, among

ABBREVIATIONS AST = acute spine trauma; ICD9-BISS = International Classification of Diseases, 9th Edition-Based Injury Severity Score; QALY = quality-adjusted life year; $\mathrm{SCl}=$ spinal cord injury.

SUBMITTED December 23, 2017. ACCEPTED February 6, 2018.

INCLUDE WHEN CITING DOI: 10.3171/2018.2.FOCUS17778. 
others. ${ }^{16,20,23,29-31,34,36}$ Nonetheless, the epidemiology of AST has been changing over the past few decades, with an escalation of fall-related AST among the aging of the population. 7,20

Moreover, AST can have a significant impact on individuals, their family members, and society. In the United States, the 1st-year total health care costs of attendant care, home modifications, and equipment for caring for individuals with traumatic spinal cord injury (SCI) were estimated to vary from US $\$ 123,000$ to US $\$ 423,000$ in 2009, depending on the level and severity of injury. ${ }^{8}$ Furthermore, the ongoing annual costs after the 1st year of injury were estimated to vary from US $\$ 33,500$ to US $\$ 150,500{ }^{8}$ Using those costing estimations, the projected lifetime cost for an individual injured at age 25 would span up to US\$2.7 million depending on level of injury. ${ }^{6}$ Given the substantial economic impact of treating this condition in the short- and long-term, AST should attract greater attention from health care providers, administrators, and health care decision makers working in an economically constrained health care system.

In addition to the substantial economic burden associated with AST, there are other pressing reasons for a better understanding of the potential cost-saving opportunities in the area of health economics in AST, including increasing health care costs associated with new technologies and therapies, and aging of the population. ${ }^{9,19}$ Understanding the near- and long-term economic consequences of AST surgical decision-making is paramount to informing health care policy makers and administrators in identifying interventions that will reduce the burden of AST while minimizing total direct costs from a health system perspective. Given this, we carried out this scoping review of the literature in order to identify, synthetize, and analyze the current knowledge on the health economics of AST.

\section{Methods}

This systematic review and scoping synthesis included original articles focused on cost-effectiveness, cost-utility, cost-benefit, cost-minimization, cost-comparison, and economic analysis related to neurosurgical management of AST, including traumatic SCI. Editorials, commentary, conference abstracts, and case reports were excluded. For the purpose of this review, AST was defined as trauma to the spine that may result in SCI with motor, sensory, and/ or autonomic impairment.

The primary literature search was carried out using MEDLINE, the Excerpta Medica database (EMBASE), the Cumulative Index to Nursing and Allied Health Literature (CINAHL), the Cochrane Controlled Trials Register (CCTR), and PubMed without limits to language or individual age at the time of AST from 1946 to September 27, 2017. The literature search used the following terms: (cost analysis, cost effectiveness, cost benefit, economic evaluation or economic impact) AND (spine or spinal cord) AND (surgery or surgical). All titles and abstracts were screened by a single reviewer who selected the articles according to the inclusion and exclusion criteria. A secondary search was carried out using the reference list from the articles captured in the primary literature search. All selected articles were eventually reviewed and their data were abstracted into tables, synthesized, and analyzed. Outcomes of interest included costs, cost per quality-adjusted life year (QALY), and cost per clinical outcome.

Because there is no consensus-derived quality assessment currently available for economic studies, we used well-recognized specific reporting checklists to indirectly evaluate the quality of the economic studies. The costeffectiveness and cost-utility studies were evaluated using the Drummond checklist ${ }^{10}$ and the Consolidated Health Economic Evaluation Reporting Standards (CHEERS) checklist ${ }^{18}$ while the cost studies were examined using a checklist presented in a critical review of cost-of-illness studies by Larg and Moss. ${ }^{21}$

\section{Results}

The primary literature search captured 5770 titles, of which a total of 11 studies were deemed to meet the inclusion and exclusion criteria (Fig. 1). The secondary literature search did not capture additional articles. Overall, there were 4 cost-utility analyses, 5 cost analyses that compared the cost of intervention with a comparator, and 2 studies that examined costs without a comparator.

The majority of the studies ( 8 of 11) were published in the last 6 years. The patient population varied in the studies, with 3 on traumatic thoracolumbar spine fracture, 3 on traumatic cervical spine fracture, 2 on traumatic cervical SCI, 2 on thoracolumbar burst fractures, and 1 on geriatric type-II odontoid fracture (Table 1). Pooling data for analysis was precluded due to the heterogeneity of patient populations, clinical entities, surgical interventions, and outcomes of interest. Overall, no main methodological issues were identified among the cost-effectiveness studies (Tables 2 and 3, respectively). The majority of the cost studies and cost-comparison studies showed no major methodological issues recognized by the checklist based on a critical review of cost-of-illness studies by Lang and Moss (Table 4).

\section{Cost-Effectiveness Studies in Cervical Spine Surgery}

Furlan et al. examined the cost-effectiveness of early (within 24 hours) versus delayed surgical decompression of the spinal cord among individuals with SCI. ${ }^{14}$ This costutility analysis was undertaken under the perspective of a publicly funded insurer. Clinical and utility data were derived from a prior multicenter observational study. ${ }^{11}$ The costs included all direct hospital costs in a spine trauma center and inpatient rehabilitation for the initial 6 months after AST. For individuals with motor complete SCI, the total cost for early decompression was approximately US $\$ 11,000$ (in 2014) less than that for delayed decompression, with an incremental utility difference of 0.0002 . For motor incomplete SCI, individuals with early decompression showed US $\$ 5000$ lower costs and 0.01 higher utilities compared to delayed decompression. In the probabilistic sensitivity analyses for motor complete SCI, there was a 53\% probability that the early decompression is more cost-effective than delayed surgery at all willingness-to- 


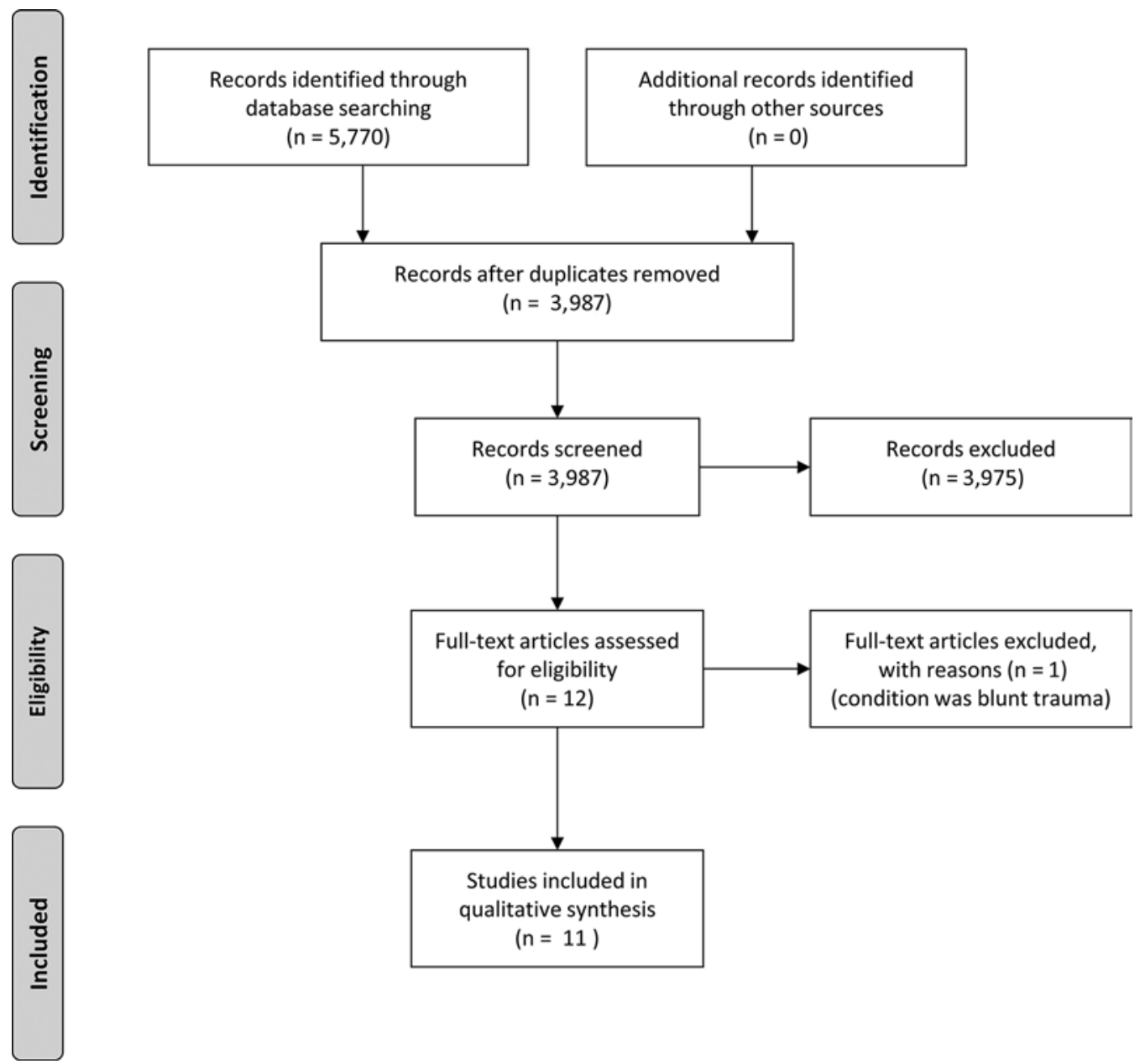

FIG. 1. Preferred Reporting Items for Systematic Reviews and Meta-Analyses (PRISMA) ${ }^{26}$ inclusion flow diagram.

pay thresholds. For motor incomplete SCI, this probability increased to $59 \%-60 \%$ at all thresholds. The incremental cost-effectiveness ratio analysis indicated a saving of US\$58,368,024 per QALY gained for patients with com- plete SCI and a saving of US\$536,217 per QALY gained in patients with incomplete SCI for the early spinal decompression. The authors concluded that early surgical decompression of the spinal cord decreases health care

TABLE 1. Details of studies included in our scoping review

\begin{tabular}{|c|c|c|c|c|c|}
\hline Author \& Year & $\begin{array}{l}\text { Population } \\
\text { Jurisdiction }\end{array}$ & Study Type & Patient Condition & Intervention & Comparator \\
\hline Aras et al., 2016 & Denmark & Cost comparison & Thoracolumbar burst fracture & Surgical & Conservative \\
\hline Barlow et al., 2016 & US & Cost-utility analysis & Geriatric type-II odontoid fracture & Operative & Nonoperative \\
\hline Boakye et al., 2012 & US & Cost comparison & Thoracolumbar fracture & Early fixation & Late fixation \\
\hline Furlan et al., $2016^{14}$ & Canada & Cost-utility analysis & Cervical SCl & Early decompression & Delayed decompression \\
\hline Furlan et al., $2016^{13}$ & Canada & Cost-utility analysis & Cervical SCl & Elderly & Non-elderly \\
\hline Lee et al., 2017 & South Korea & Cost-utility analysis & Thoracolumbar burst fracture & Pedicle screw removal & No screw removal \\
\hline Medress et al., 2015 & US & Cost comparison & Cervical fracture & Early surgery & Late surgery \\
\hline Nandyala et al., 2013 & US & Cost comparison & Cervical spine trauma & Weekend admission & Weekday admission \\
\hline Siebenga et al., 2007 & Netherlands & Cost comparison & Thoracolumbar spine fracture & Surgical & Nonsurgical \\
\hline van der Roer et al., 2005 & Netherlands & Cost analysis & Thoracolumbar spine fracture & Not applicable & NA \\
\hline Watts et al., 1993 & US & Cost analysis & Unstable SCl & Sublaminar wiring & NA \\
\hline
\end{tabular}

$\mathrm{NA}=$ not applicable. 
TABLE 2. Results of the economic evaluation checklist by Drummond et al.

\begin{tabular}{|c|c|c|c|c|}
\hline & $\begin{array}{c}\text { Barlow et al., } \\
2016\end{array}$ & $\begin{array}{c}\text { Furlan et al., } \\
2016^{14}\end{array}$ & $\begin{array}{c}\text { Furlan et al., } \\
2016^{13}\end{array}$ & $\begin{array}{l}\text { Lee et al., } \\
2017\end{array}$ \\
\hline \multicolumn{5}{|l|}{ Study design } \\
\hline The research question is stated. & Yes & Yes & Yes & Yes \\
\hline The economic importance of the research question is stated. & Yes & Yes & Yes & Yes \\
\hline The viewpoint(s) of the analysis are clearly stated and justified. & Yes & Yes & Yes & Yes \\
\hline The rationale for choosing the alternative programmes or interventions compared is stated. & Yes & Yes & Yes & Yes \\
\hline The alternatives being compared are clearly described. & Yes & Yes & Yes & Yes \\
\hline The form of economic evaluation used is stated. & Yes & Yes & Yes & Yes \\
\hline The choice of form of economic evaluation is justified in relation to the questions addressed. & Yes & Yes & Yes & Yes \\
\hline \multicolumn{5}{|l|}{ Data collection } \\
\hline The source(s) of effectiveness estimates used are stated. & Yes & Yes & Yes & Yes \\
\hline Details of the design and results of effectiveness study are given (if based on a single study). & Yes & Yes & NA & Yes \\
\hline $\begin{array}{l}\text { Details of the method of synthesis or meta-analysis of estimates are given (if based on an } \\
\text { overview of a number of effectiveness studies). }\end{array}$ & NA & NA & Yes & NA \\
\hline The primary outcome measure for the economic evaluation is clearly stated. & Yes & Yes & Yes & Yes \\
\hline Methods to value health states and other benefits are stated. & Yes & Yes & Yes & Yes \\
\hline Details of the subjects from whom valuations were obtained are given. & No & Yes & Yes & Yes \\
\hline Productivity changes (if included) are reported separately. & NA & NA & NA & NA \\
\hline The relevance of productivity changes to the study question is discussed. & NA & NA & NA & NA \\
\hline Quantities of resources are reported separately from their unit costs. & Yes & Yes & Yes & NA \\
\hline Methods for the estimation of quantities and unit costs are described. & Yes & Yes & Yes & Yes \\
\hline Currency and price data are recorded. & Yes & Yes & Yes & Yes \\
\hline Details of currency of price adjustments for inflation or currency conversion are given. & Yes & Yes & Yes & No \\
\hline Details of any model used are given. & Yes & Yes & Yes & NA \\
\hline The choice of model used and the key parameters on which it is based are justified. & Yes & Yes & Yes & NA \\
\hline \multicolumn{5}{|l|}{ Analysis and interpretation of results } \\
\hline Time horizon of costs and benefits is stated. & Yes & Yes & Yes & Yes \\
\hline The discount rate is stated. & NA & NA & NA & Yes \\
\hline The choice of rate is justified. & NA & NA & NA & No \\
\hline An explanation is given if costs or benefits are not discounted. & Yes & Yes & Yes & NA \\
\hline Details of statistical tests and confidence intervals are given for stochastic data. & NA & Yes & Yes & Yes \\
\hline The approach to sensitivity analysis is given. & Yes & Yes & Yes & Yes \\
\hline The choice of variables for sensitivity analysis is justified. & Yes & Yes & Yes & Yes \\
\hline The ranges over which the variables are varied are stated. & Yes & Yes & Yes & Yes \\
\hline Relevant alternatives are compared. & Yes & Yes & Yes & Yes \\
\hline Incremental analysis is reported. & Yes & Yes & Yes & Yes \\
\hline Major outcomes are presented in a disaggregated as well as aggregated form. & No & Yes & Yes & Yes \\
\hline The answer to the study question is given. & Yes & Yes & Yes & Yes \\
\hline Conclusions follow from the data reported. & Yes & Yes & Yes & Yes \\
\hline Conclusions are accompanied by the appropriate caveats. & Yes & Yes & Yes & Yes \\
\hline
\end{tabular}

Based on data discussed in Drummond MF, Jefferson TO: Guidelines for authors and peer reviewers of economic submissions to the BMJ. The BMJ Economic Evaluation Working Party. BMJ 313:275-283, 1996.

costs and may marginally increase the patient's quality of life for a willingness-to-pay of US\$50,000.14

Furlan et al. carried out a cost-utility comparing younger adults (less than 65 years) versus elderly individuals with acute traumatic cervical SCI regarding their initial surgical treatment and inpatient rehabilitation. ${ }^{13}$ This costutility analysis was performed under the perspective of a publicly funded insurer in Canada. Clinical and utility data were derived from a prior multicenter observational study. ${ }^{11}$ Costing data included all hospital costs from the spine trauma center and inpatient rehabilitation within the first 6 months following AST. The mean treatment cost for elderly individuals' SCI was US\$56,600 (in 2014) higher than that for the younger group, for a mean utility difference of 0.01 lower in the elderly group. ${ }^{13}$ The incremental cost-effectiveness ratio analysis suggested an additional 
Title and abstract

Identify the study as an economic evaluation, or use more specific terms such as "cost-effective- $\quad$ Yes $\quad$ Yes Yes Yes ness analysis" and describe the intervention compared.

Provide a structured summary of objectives, perspective, setting, methods (including study design $\quad$ Yes $\quad$ Yes Yes Yes and inputs), results (including base-case and uncertainty analyses), and conclusions.

Introduction

Provide an explicit statement of the broader context for the study.

Present the study question and its relevance for health policy or practice decisions.

$\begin{array}{llll}\text { Yes } & \text { Yes } & \text { Yes } & \text { Yes } \\ \text { Yes } & \text { Yes } & \text { Yes } & \text { No }\end{array}$

Methods

Describe characteristics of the base-case population and subgroups analyzed, including why they $\quad$ Yes $\quad$ Yes Yes Yes were chosen.

State relevant aspects of the system(s) in which the decision(s) need(s) to be made.

Describe the perspective of the study and relate this to the costs being evaluated.

Describe the interventions or strategies being compared and state why they were chosen.

State the time horizon(s) over which costs and consequences are being evaluated and say why appropriate.

Report the choice of discount rate(s) used for costs and outcomes and say why appropriate.

Describe what outcomes were used as the measure(s) of benefit in the evaluation and their relevance for the type of analysis performed.

Single study-based estimates: Describe fully the design features of the single effectiveness study $\quad$ NA $\quad$ Yes Yes Yes and why the single study was a sufficient source of clinical effectiveness data OR

Synthesis-based estimates: Describe fully the methods used for the identification of included stud- $\quad$ Yes $\quad$ NA NA NA ies and synthesis of clinical effectiveness data.

If applicable, describe the population and methods used to elicit preferences for outcomes.

Single study-based economic evaluation: Describe approaches used to estimate resource use associated with the alternative interventions. Describe primary or secondary research methods for valuing each resource item in terms of its unit cost. Describe any adjustments made to approximate opportunity costs.

Model-based economic evaluation: Describe approaches and data sources used to estimate $\quad$ Yes NA NA resource use associated with model health states. Describe primary or secondary research methods for valuing each resource item in terms of its unit costs. Describe any adjustments made to approximate to opportunity costs.

Report the dates of the estimated resource quantities and unit costs. Describe methods for adjust- $\quad$ Yes $\quad$ Yes Yes Yes ing estimated unit costs to the year of reported costs if necessary. Describe methods for converting costs into a common currency base and exchange rate.

Describe and give reasons for the specific type of decision-analytic model used.

Describe all structural or other assumptions underpinning the decision-analytic model.

Describe all analytic methods supporting the evaluation.

$\begin{array}{llll}\text { No } & \text { NA } & \text { NA } & \text { yes } \\ \text { Yes } & \text { Yes } & \text { Yes } & \text { Yes } \\ \text { NA } & \text { Yes } & \text { Yes } & \text { Yes } \\ \text { Yes } & \text { NA } & \text { NA } & \text { NA } \\ \text { NA } & \text { NA } & \text { NA } & \text { NA } \\ \text { NA } & \text { Yes } & \text { Yes } & \text { Yes }\end{array}$

\begin{tabular}{llll} 
No & No & No & No \\
\hline No & Yes & Yes & Yes \\
\hline Yes & Yes & Yes & Yes \\
\hline Yes & Yes & Yes & No
\end{tabular}

Results

Report the values, ranges, reference, and if used, probability distribution for all parameters. Report $\quad$ Yes $\quad$ Yes $\quad$ Yes $\quad$ Yes reasons or sources for distributions used to represent uncertainty where appropriate.

For each intervention, report mean values for the main categories of estimated costs and outcomes Yes Yes Yes Yes of interest, as well as mean difference between the comparator groups. If applicable, report incremental cost-effectiveness ratios.

Single study-based economic evaluation: Describe the effects of sampling uncertainty for estimat- $\quad$ NA $\quad$ Yes Yes No ing incremental cost, incremental effectiveness, and incremental cost-effectiveness, together with the impact of methodological assumptions.

Model-based economic evaluation: Describe the effects on the results of uncertainty for all input $\quad$ Yes NA NA parameters, and uncertainty related to the structure of the model and assumptions. 


\begin{tabular}{|c|c|c|c|c|}
\hline & $\begin{array}{l}\text { Barlow et } \\
\text { al., } 2016\end{array}$ & $\begin{array}{l}\text { Furlan et } \\
\text { al., } 2016^{14}\end{array}$ & $\begin{array}{l}\text { Furlan et } \\
\text { al., } 2016^{13}\end{array}$ & $\begin{array}{l}\text { Lee et } \\
\text { al., } 2017\end{array}$ \\
\hline $\begin{array}{l}\text { If applicable, report differences in costs, outcomes, or cost-effectiveness that can be explained } \\
\text { by variations between subgroups of patients with different baseline characteristics or other } \\
\text { observed variability in effects that are not reducible by more information. }\end{array}$ & Yes & No & No & No \\
\hline \multicolumn{5}{|l|}{ Discussion } \\
\hline $\begin{array}{l}\text { Summarize key study findings and describe how they support the conclusions reached. Discuss } \\
\text { limitations and the generalizability of the findings and how the findings fit with current knowledge. }\end{array}$ & Yes & Yes & Yes & Yes \\
\hline \multicolumn{5}{|l|}{ Other } \\
\hline $\begin{array}{l}\text { Describe how the study was funded and the role of the funder in the identification, design, conduct, } \\
\text { and reporting of the analysis. Describe other nonmonetary sources of support. }\end{array}$ & Yes & Yes & Yes & Yes \\
\hline $\begin{array}{l}\text { Describe any potential for conflict of interest among study contributors in accordance with journal } \\
\text { policy. }\end{array}$ & Yes & Yes & Yes & Yes \\
\hline
\end{tabular}

Based on CHEERS checklist. From Husereau D, Drummond M, Petrou S, Carswell C, Moher D, Greenberg D, et al: Consolidated Health Economic Evaluation Reporting Standards (CHEERS) statement. BMC Med 11:80-7015-7011-7080, 2013. CC-BY-NC 3.0 license (https://creativecommons.org/licenses/by-nc/3.0/).

cost of US\$5,655,557 per QALY gained when managing elderly patients compared to younger individuals with SCI. ${ }^{13}$ The authors concluded that surgical management and rehabilitation of acute traumatic cervical SCI in the elderly are costlier but similarly effective when compared to younger adults. ${ }^{13}$

Barlow et al. conducted a cost-effectiveness comparison of operative versus nonoperative treatment of individuals 64 years and older with type-II odontoid fractures who were treated at a trauma center in New England. ${ }^{3}$ This cost-utility analysis was apparently undertaken under the perspective of multiple private insurers in the United States. Results were stratified into the following age groups: 65-74 years, 75-84 years, and 85 years or older at the time of AST. The authors reported that operative treatment was more costly than nonoperative treatment at 1 year for all age groups, whereas operative treatment only resulted in greater QALYs for the 2 younger groups, with a cost of US $\$ 12,078$ (in 2013) per QALY for the 65to 74-year age group, and US\$40,467 per QALY for the 75- to 84 -year age group. ${ }^{3}$ Nonoperative treatment was considered the dominant approach when compared to operative treatment for individuals older than 84 years, for a willingness-to-pay of US $\$ 100,000 .^{3}$ The authors concluded that operative treatment was likely cost-effective for individuals between 65 and 84 years of age; however, operative treatment was more costly and less effective for individuals older than 85 years. ${ }^{3}$

\section{Cost-Effectiveness Studies in Thoracolumbar Spine Surgery}

Aras et al. performed a cost-effectiveness study comparing surgical treatment to conservative management for thoracolumbar burst fractures. ${ }^{1}$ This cost-effectiveness analysis was undertaken under the perspective of a taxfunded state-run universal health care system in Denmark. This study included consecutive patients with CT-verified incomplete burst fractures of the T11-L2 vertebrae who were admitted to a university hospital. All hospital, emergency department, and health care provider costs incurred from diagnosis up to 2 years were included. ${ }^{1}$ The effectiveness outcome of interest was use of oral morphine equivalent and daily doses of narcotic/nonnarcotic analgesics. While the health care costs for the group requiring surgery were EUR 10,734 (in 2010) higher than those treated nonsurgically matched for age and sex, there were no significant differences between the study groups for the effectiveness outcomes. ${ }^{1}$ The probabilistic sensitivity analysis showed that the probability of surgery being costeffective compared to no surgery was below $50 \%$ for all effectiveness outcomes at all willingness-to-pay thresholds. The authors concluded that surgical treatment for thoracolumbar burst fractures was not cost-effective compared to nonsurgical approach.

Lee et al. examined the cost-effectiveness of removing the pedicle screw after successful posterior instrumented fusion versus leaving the screw for individuals with thoracolumbar burst fractures. ${ }^{22}$ This cost-utility analysis was undertaken under the perspective of a publicly funded insurer in South Korea. This study included all inpatient hospital expenses, physician fees, and medication costs within a 2-year horizon using a discount rate of $3 \%$ a year. $^{22}$ There were higher costs-increase of US\$2529 (in 2016) at 1 year and US\$2592 at 2 years-in the intervention arm due to the additional surgery to remove the screw. However, there was a QALY gain of 0.097 at 1 year and 0.201 at 2 years for the intervention group. Removal of the pedicle screw resulted in an incremental cost-effectiveness ratio of US\$26,072 per QALY at 1 year and US $\$ 13,125$ per QALY at 2 years when compared to the group of patients without removal of the pedicle screws. ${ }^{22}$ The authors concluded that removal of the pedicle screws between 1 and 2 years after the initial surgical treatment of thoracolumbar burst fractures was considered more cost-effective than not removing the pedicle screws. ${ }^{22}$

\section{Cost-Comparison Studies in Cervical Spine Surgery}

Medress et al. examined the economic impact of early (within 72 hours of hospital admission) and late surgery in the management of individuals with traumatic cervical 
TABLE 4. Results of the cost-of-illness checklist for cost analyses included in our review

$\begin{array}{ccccccc} & \text { Boakye } & \text { Medress } & \text { Nandyala } & \text { Siebenga } & \text { van der } & \text { Watts } \\ \text { Aras et } & \text { et al., } & \text { et al., } & \text { et al., } & \text { et al., } & \text { Roer et } & \text { et al., } \\ \text { al., 2016 } & 2012 & 2015 & 2013 & 2007 & \text { al., 2005 } & 1993\end{array}$

1) Analytical framework: what costs should have been measured?

a) What was the motivation and perspective of the study?

Health Hospital Hospital Hospital Societal Hospital Hospital care

sector

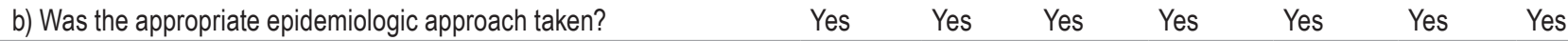

c) Was the study question well specified?

i) Were all relevant, non-trial cost components and their stakeholders Yes $\quad$ Yes $\quad$ Yes $\quad$ Yes $\quad$ Yes Yes No identified?

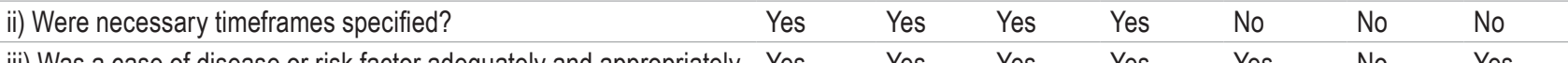

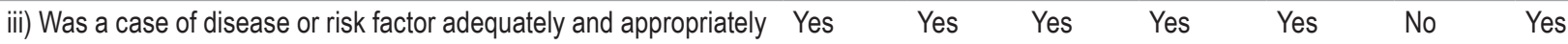
defined?

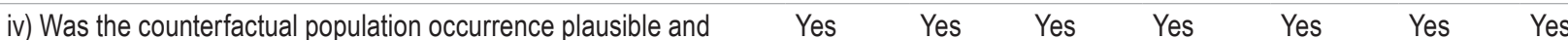
meaningful?

2) Methodology and data: how well were resource use and productivity

losses measured?

a) Was an appropriate method(s) of quantification used, such that

$\begin{array}{llllllll}\text { i) Additional, or excess, costs were measured? } & \text { Yes } & \text { Yes } & \text { Yes } & \text { Yes } & \text { Yes } & \text { Yes } & \text { Yes } \\ \text { ii) Only costs specific to (caused by) the health problem were } & \text { Yes } & \text { Yes } & \text { Yes } & \text { No } & \text { Yes } & \text { No } & \text { Yes }\end{array}$ included (confounders controlled)?

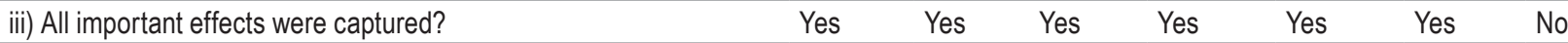

iv) Important differences across subpopulations were accounted for? Yes $\quad$ Yes $\quad$ Yes $\quad$ Yes $\quad$ Yes $\quad$ Yes No

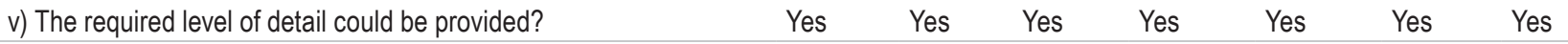

b) Was the resource quantification method(s) well executed?

i) For population-based studies, were cost allocation methods, data NA $\quad$ NA NA NA NA NA NA and assumptions valid?

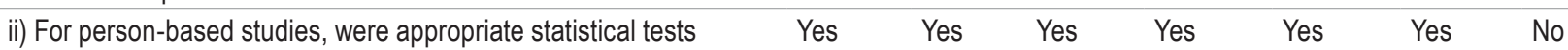
performed and reported?

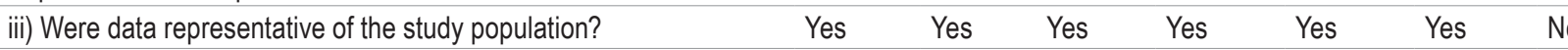

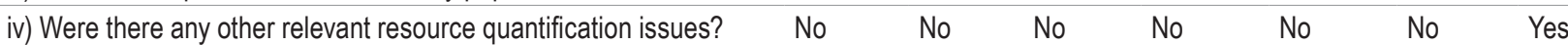

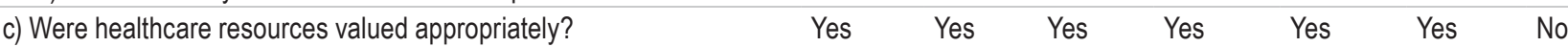

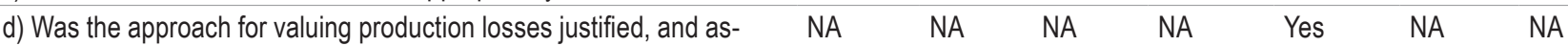
sumptions valid?

e) Was the inclusion of intangible costs appropriate:

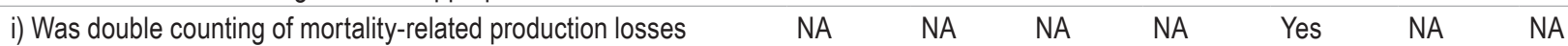
avoided?

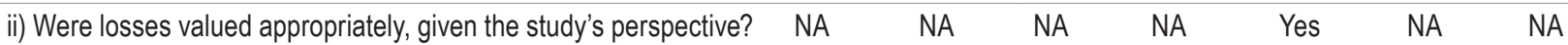

3) Analysis and reporting

\begin{tabular}{|c|c|c|c|c|c|c|c|}
\hline a) Did the analysis address the study question? & Yes & Yes & Yes & Yes & Yes & Yes & Yes \\
\hline b) Was a range of estimates presented? & Yes & No & No & No & No & Yes & No \\
\hline c) Were the main uncertainties identified? & No & No & No & No & No & No & No \\
\hline \multicolumn{8}{|l|}{ d) Was a sensitivity analysis performed on: } \\
\hline i) Important (uncertain) parameter estimates? & No & No & No & No & No & No & No \\
\hline ii) Key assumptions? (including the counterfactual) & No & No & No & No & No & No & No \\
\hline iii) Point estimate? (based on confidence or credible intervals) & No & No & No & No & No & No & No \\
\hline $\begin{array}{l}\text { e) Was adequate documentation and justification given for cost compo- } \\
\text { nents, data and sources, assumptions and methods? }\end{array}$ & Yes & Yes & Yes & Yes & Yes & Yes & No \\
\hline $\begin{array}{l}\text { f) Was uncertainty around the estimates and its implications adequately } \\
\text { discussed? }\end{array}$ & No & No & No & No & No & No & No \\
\hline
\end{tabular}




\begin{tabular}{|c|c|c|c|c|c|c|c|}
\hline & $\begin{array}{l}\text { Aras et } \\
\text { al., } 2016\end{array}$ & $\begin{array}{l}\text { Boakye } \\
\text { et al., } \\
2012\end{array}$ & $\begin{array}{l}\text { Medress } \\
\text { et al., } \\
2015\end{array}$ & $\begin{array}{l}\text { Nandyala } \\
\text { et al., } \\
2013\end{array}$ & $\begin{array}{l}\text { Siebenga } \\
\text { et al., } \\
2007\end{array}$ & $\begin{array}{l}\text { van der } \\
\text { Roer et } \\
\text { al., } 2005\end{array}$ & $\begin{array}{l}\text { Watts } \\
\text { et al., } \\
1993\end{array}$ \\
\hline \multicolumn{8}{|l|}{ 3) Analysis and reporting (continued) } \\
\hline $\begin{array}{l}\text { g) Were important limitations discussed regarding the cost compo- } \\
\text { nents, data, assumptions and methods? }\end{array}$ & Yes & Yes & Yes & Yes & No & Yes & No \\
\hline $\begin{array}{l}\text { h) Were the results presented at the appropriate level of detail to } \\
\text { answer the study question (cost components; disease subtypes, } \\
\text { severity, stage; subpopulation groups, cost bearers)? }\end{array}$ & Yes & Yes & Yes & Yes & Yes & Yes & No \\
\hline
\end{tabular}

The checklist in the first column of this table originally appeared as Fig. 1 in Larg and Moss. ${ }^{21}$ Reprinted by permission from Springer Nature: Pharmacoeconomics 29: 653-671, Cost-of-illness studies: a guide to critical evaluation. Larg A, Moss JR. Copyright 2011.

fractures. ${ }^{25}$ Using a propensity score method, both study groups were selected by matching for age, emergency department admission, hospital, expected payer, surgical approach, comorbidities, and ICD9-BISS (International Classification of Diseases, 9th Edition-Based Injury Severity Score). Costing data of hospital admissions in California from 2006 to 2009 (except for downstream costs) were included. The authors concluded that initial hospital costs were significantly lower for the individuals who underwent early surgery (US\$63,065 in 2009) than for the late surgery group (US $\$ 77,049) .{ }^{25}$

Nandyala et al. compared the hospital costs of weekday versus weekend admissions for management of individuals with AST who underwent cervical fusion. ${ }^{27}$ Using the Nationwide Inpatient Sample database, all hospital costs for the management of individuals with AST who were admitted to over 1000 hospitals in 46 American states from 2002 to 2010 were included. Their results suggest that the hospital costs were significantly greater for the patients who were admitted on the weekend than for those who were admitted on a weekday (a mean of US $\$ 10,045$ higher for those treated with anterior cervical fusion, US\$10,227 higher for those who underwent posterior cervical fusion, and US $\$ 11,301$ higher for those who had anterior and posterior cervical fusion). However, there were significant differences between the study groups regarding their mean age, sex, and number of preexisting medical comorbidities, which could affect the results. ${ }^{27}$

\section{Cost-Comparison Studies in Thoracolumbar Spine Surgery}

Boakye et al. examined the economic impact of early (within 72 hours of hospital admission) versus late fracture fixation surgery for individuals with traumatic thoracolumbar fractures. ${ }^{4}$ This study included the charges of hospital admissions in several institutions in California from 2003 to 2008 (no downstream cost was included). Using a propensity score method, the study groups were matched for admission location, age, sex, comorbidity score, insurance type, and injury severity score (ICD9BISS). The authors concluded that hospital charges for individuals who underwent early surgery were US $\$ 38,120$ lower than hospital charges for the later surgery group (US $\$ 213,031$ vs US $\$ 251,151$, respectively). ${ }^{4}$
Siebenga et al. compared surgical versus nonsurgical treatment for management of individuals with traumatic thoracolumbar spine fractures..$^{32}$ This study included direct costs, general-practitioner visit and absenteeism costs, and private health care expenditures of individuals with traumatic thoracolumbar spine fractures (T10-L4 compression fracture without neurological deficit) who were treated between 1998 and 2003 in a European institution. Mean direct costs during this time period for the surgical treatment (US\$21,960) were significantly higher than those for the conservative management (US\$11,880). However, the general-practitioner visit costs, private expenditures, and absenteeism costs for the surgical group (US\$13, US\$550, and US\$6630, respectively) were significantly lower than those for the nonsurgical group (US $\$ 34$, US $\$ 816$, and US $\$ 10,329$, respectively). ${ }^{32}$

\section{Costing Study in Cervical Spine Surgery}

Watts et al. provide a list of the costs of posterior fusion with sublaminar wiring for management of individuals with acute traumatic, unstable cervical spine injury who underwent surgery at the University of Missouri from 1984 to 1989 and at the University of Maryland from 1991 to $1991 .^{35}$ The costs for supplies were estimated to be US\$2700 (in 1993) for the Haid plate, US\$2640 for the Halifax clamp, and US $\$ 5.94$ for the wiring system..$^{35}$

\section{Costing Study in Thoracolumbar Spine Surgery}

Van der Roer et al. examined the cost of inpatient hospital and outpatient care for management of individuals with traumatic thoracolumbar spine fractures in a single institution in the Netherlands. ${ }^{33}$ The total mean cost to the individual with spine fracture who underwent surgical treatment was EUR 19,700 (in 2001), whereas the mean cost for those individuals who underwent conservative management was EUR 12,500.33

\section{Discussion}

Results of this scoping review underline a few potentially cost-saving strategies in the neurosurgical management of individuals with AST. Early surgical treatment may be more cost-effective (or less costly) than delayed surgery in the management of individuals with acute traumatic cervi- 
cal SCI (or traumatic thoracolumbar or cervical fractures). The initial surgical treatment and inpatient rehabilitation for the management of elderly individuals with acute traumatic cervical SCI is more costly but similarly effective to that for the younger individuals. Surgical treatment of the elderly with type-II odontoid fractures is more costly than the nonoperative approach; however, surgical treatment is more effective than the nonoperative approach among individuals whose age at the time of AST is between 65 and 84 years. Surgical treatment of traumatic thoracolumbar spine fractures is implicated in greater direct costs but lower general-practitioner visit costs, private expenditures, and absenteeism costs than nonsurgical management. Removal of pedicle screws from 1 to 2 years after posterior instrumented fusion for individuals with thoracolumbar burst fractures is more cost-effective than no removal of the pedicle screws.

The number of cases of AST appears to be increasing with time in many jurisdictions. Trends in admission of traumatic spine injury at a trauma center in Ontario (Canada) show an increase in admissions over time well beyond population growth. ${ }^{30}$ With the substantial cost for treating each injured patient, there will be an increasing need to identify and implement interventions that show both efficacy and value. With hospitals facing fiscal restraint and mean length of hospital stay remaining unchanged over time, there is an opportunity and need for improvements in efficiency of management of patients with AST. ${ }^{20}$ This scoping review identified a few potentially cost-saving strategies in the management of AST that should be considered by neurosurgeons, policy makers, and administrators. Efficiency may be improved through adjusting the timing of neurosurgical treatment. For instance, early surgical decompression of the spinal cord (within 24 hours from injury) may be cost-saving with similar outcomes in the management of individuals with acute traumatic cervical SCI. ${ }^{14}$ Interestingly, a recent benchmarking process analysis of surgical decompression after traumatic cervical spine injury revealed that health-related factors were the most important determinants of the delay in the surgical decompression of the spinal cord. ${ }^{17}$ The same benchmarking analysis also showed that patients who underwent early surgery had a significantly shorter waiting time, shorter waiting time for assessment by a spine surgeon, and a shorter waiting time for a surgical decision than did the patients in the delayed surgery group. ${ }^{17}$ Perhaps not surprisingly, neurosurgeons' availability and decision-making process can directly affect the health care efficiency and costs.

This review also underscores other potentially costsaving opportunities for neurosurgeons in the area of AST. Cost-savings could also be realized through early fracture fixation surgery for individuals with traumatic thoracolumbar or cervical spine fractures. ${ }^{4,25}$ Furthermore, the treatment choice between surgical and nonsurgical treatment is also an area where efficiency may be improved. For instance, surgical treatment of traumatic thoracolumbar burst fractures and surgical treatment of type-II odontoid fractures for individuals over 65 years of age were both found to be non-cost-effective compared to conservative treatment. ${ }^{1,3}$ Those results suggest that these inter- ventions could save health care costs while not decreasing patient outcomes.

Although this review did not capture a single study on the cost-saving magnitude preventative interventions, it is obvious that prevention of AST represents a great opportunity to reduce disability and health care costs. Various studies have reported that SCIs due to motor vehicle accidents have been decreasing while injury due to falls is on the rise..$^{20,28,30}$ The population group at risk for fall-related SCI tends to be older than the rest of the population..$^{12,34,36}$ Fall-prevention strategies in the elderly may help reduce the number of future cases of fall-related AST as emphasized in a recent literature review by the Canadian Agency for Drugs and Technologies in Health. ${ }^{5}$ Overall, 9 studies documented that fall-prevention strategies can be cost-effective and in some cases cost-saving. ${ }^{5}$

The combination of a comprehensive fall-prevention strategy along with a conservative approach to treating spine trauma and early intervention where surgery is preferred may result in a substantial reduction in the economic burden on the health care system. Moreover, additional economic analyses for other interventions to treat individuals with traumatic spinal injury would lead to the identification of other potential ways to improve patient care in a fiscally responsible manner.

\section{Study Limitations}

While this is a comprehensive review of the literature that stresses some of the potential economic impact of neurosurgeons' decisions when managing AST, our review has limitations that must be taken into account when applying its results.

First, although our search strategy for peer-reviewed literature was comprehensive, this review did not include a search for "gray literature" where economic evaluations conducted by health technology assessment agencies or similar organizations are usually published. Given the limited peer-reviewed literature and the relatively low incidence of AST, it is unlikely that a health technology assessment agency has conducted an economic evaluation on this population. Second, most (if not all) of the economic studies included in this review have limited generalizability that is intrinsic to their study design and population. Third, the study selection for our review was limited to a single reviewer. While the other authors assisted in the refinement of the selection of the studies prior to data extraction and synthesis, there is still the possibility that relevant studies may have been filtered out by the reviewer. Fourth, the discrepancies of the health care coverage and accessibility among different jurisdictions impose limitations to the applicability and economic effects of the practice and policy changes supported by those prior studies in the literature. Fifth, all studies captured in this review were carried out in highincome countries where resources are commonly and widely available for the vast majority of their population; hence, those results may not be generalizable across the world. Finally, stakeholders such as health care decision makers were not consulted during the study development to provide an additional perspective and to validate study findings. Although Arksey and O'Malley ${ }^{2}$ consider this 
optional for a scoping study, Levac et al. ${ }^{24}$ endorse that inclusion of stakeholders in the scoping review development should be a required step because it provides additional methodological rigor.

\section{Conclusions}

This review stresses potentially cost-effective neurosurgical strategies, including early surgical treatment compared to delayed surgery for acute traumatic cervical SCI, traumatic thoracolumbar and cervical fractures, surgical treatment for type-II odontoid fracture in patients 65-84 years old, and removal of pedicle screws within the first 2 years after posterior instrumented fusion for thoracolumbar burst fractures. However, those results were based on single studies of selected population groups that were managed in distinct jurisdictions, limiting their generalizability. Finally, there are significant knowledge gaps regarding the economic impact of therapeutic choices that are commonly used by neurosurgeons when managing patients with AST.

\section{Acknowledgments}

We gratefully acknowledge the assistance from Mrs. Maureen Pakosh (BA, MISt), who works as an Information Specialist at University Health Network Library \& Information Services.

\section{References}

1. Aras EL, Bunger C, Hansen ES, Søgaard R: Costeffectiveness of surgical versus conservative treatment for thoracolumbar burst fractures. Spine (Phila Pa 1976) 41:337-343, 2016

2. Arksey H, O'Malley L: Scoping studies: towards a methodological framework. Int J Soc Res Methodol 8:19-32, 2005

3. Barlow DR, Higgins BT, Ozanne EM, Tosteson AN, Pearson AM: Cost effectiveness of operative versus non-operative treatment of geriatric type-II odontoid fracture. Spine (Phila Pa 1976) 41:610-617, 2016

4. Boakye M, Arrigo RT, Hayden Gephart MG, Zygourakis CC, Lad S: Retrospective, propensity score-matched cohort study examining timing of fracture fixation for traumatic thoracolumbar fractures. J Neurotrauma 29:2220-2225, 2012

5. Canadian Agency for Drugs and Technology in Health: Fall Prevention Strategies for Adult Patients: Comparative Effectiveness, Cost Effectiveness, and Guidelines. Ottawa: CADTH, 2016 (https://www.cadth.ca/fall-preventionstrategies-adult-patients-comparative-effectiveness-costeffectiveness-and-0) [Accessed March 16, 2018]

6. Cao Y, Chen Y, DeVivo MJ: Lifetime direct costs after spinal cord injury. Top Spinal Cord Inj Rehabil 16:10-16, 2011

7. Chen Y, He Y, DeVivo MJ: Changing demographics and injury profile of new traumatic spinal cord injuries in the United States, 1972-2014. Arch Phys Med Rehabil 97:16101619,2016

8. DeVivo MJ, Chen Y, Mennemeyer ST, Deutsch A: Costs of care following spinal cord injury. Top Spinal Cord Inj Rehabil 16:1-9, 2011

9. Dieleman JL, Baral R, Birger M, Bui AL, Bulchis A, Chapin A, et al: US spending on personal health care and public health, 1996-2013. JAMA 316:2627-2646, 2016

10. Drummond MF, Jefferson TO: Guidelines for authors and peer reviewers of economic submissions to the BMJ. BMJ 313:275-283, 1996
11. Fehlings MG, Vaccaro A, Wilson JR, Singh A, W Cadotte D, Harrop JS, et al: Early versus delayed decompression for traumatic cervical spinal cord injury: results of the Surgical Timing in Acute Spinal Cord Injury Study (STASCIS). PLoS One 7:e32037, 2012

12. Fredø HL, Rizvi SA, Lied B, Rønning P, Helseth E: The epidemiology of traumatic cervical spine fractures: a prospective population study from Norway. Scand J Trauma Resusc Emerg Med 20:85, 2012

13. Furlan JC, Craven BC, Fehlings MG: Surgical management of the elderly with traumatic cervical spinal cord injury: a cost-utility analysis. Neurosurgery 79:418-425, 2016

14. Furlan JC, Craven BC, Massicotte EM, Fehlings MG: Early versus delayed surgical decompression of spinal cord after traumatic cervical spinal cord injury: a cost-utility analysis. World Neurosurg 88:166-174, 2016

15. Furlan JC, Sakakibara BM, Miller WC, Krassioukov AV: Global incidence and prevalence of traumatic spinal cord injury. Can J Neurol Sci 40:456-464, 2013

16. Furlan JC, Tator CH: Global epidemiology of traumatic spinal cord injury, in Morganti-Kossmann C, Raghupathi R, Mass A (eds): Traumatic Brain and Spinal Cord Injury. Challenges and Developments. Cambridge, UK: Cambridge University Press, 2012, pp 216-228

17. Furlan JC, Tung K, Fehlings MG: Process benchmarking appraisal of surgical decompression of spinal cord following traumatic cervical spinal cord injury: opportunities to reduce delays in surgical management. J Neurotrauma 30:487-491, 2013

18. Husereau D, Drummond M, Petrou S, Carswell C, Moher D, Greenberg D, et al: Consolidated Health Economic Evaluation Reporting Standards (CHEERS) statement. BMC Med 11:80, 2013

19. Jain NB, Ayers GD, Peterson EN, Harris MB, Morse L, O'Connor KC, et al: Traumatic spinal cord injury in the United States, 1993-2012. JAMA 313:2236-2243, 2015

20. Kattail D, Furlan JC, Fehlings MG: Epidemiology and clinical outcomes of acute spine trauma and spinal cord injury: experience from a specialized spine trauma center in Canada in comparison with a large national registry. J Trauma 67:936-943, 2009

21. Larg A, Moss JR: Cost-of-illness studies: a guide to critical evaluation. Pharmacoeconomics 29:653-671, 2011

22. Lee HD, Jeon CH, Chung NS, Seo YW: Cost-utility analysis of pedicle screw removal after successful posterior instrumented fusion in thoracolumbar burst fractures. Spine (Phila Pa 1976) 42:E926-E932, 2017

23. Leucht P, Fischer K, Muhr G, Mueller EJ: Epidemiology of traumatic spine fractures. Injury 40:166-172, 2009

24. Levac D, Colquhoun H, O'Brien KK: Scoping studies: advancing the methodology. Implement Sci 5:69, 2010

25. Medress Z, Arrigo RT, Hayden Gephart M, Zygourakis CC, Boakye M: Cervical fracture stabilization within 72 hours of injury is associated with decreased hospitalization costs with comparable perioperative outcomes in a propensity scorematched cohort. Cureus 7:e244, 2015

26. Moher D, Liberati A, Tetzlaff J, Altman DG: Preferred reporting items for systematic reviews and meta-analyses: the PRISMA statement. PLoS Med 6:e1000097, 2009

27. Nandyala SV, Marquez-Lara A, Fineberg SJ, Schmitt DR, Singh K: Comparison of perioperative outcomes and cost of spinal fusion for cervical trauma: weekday versus weekend admissions. Spine (Phila Pa 1976) 38:2178-2183, 2013

28. O'Connor PJ: Trends in spinal cord injury. Accid Anal Prev 38:71-77, 2006

29. Oliver M, Inaba K, Tang A, Branco BC, Barmparas G, Schnüriger $\mathrm{B}$, et al: The changing epidemiology of spinal trauma: a 13-year review from a Level I trauma centre. Injury 43:1296-1300, 2012 
30. Pirouzmand F: Epidemiological trends of spine and spinal cord injuries in the largest Canadian adult trauma center from 1986 to 2006. J Neurosurg Spine 12:131-140, 2010

31. Roche SJ, Sloane PA, McCabe JP: Epidemiology of spine trauma in an Irish regional trauma unit: a 4-year study. Injury 39:436-442, 2008

32. Siebenga J, Segers MJ, Leferink VJ, Elzinga MJ, Bakker FC, Duis HJ, et al: Cost-effectiveness of the treatment of traumatic thoracolumbar spine fractures: nonsurgical or surgical therapy? Indian J Orthop 41:332-336, 2007

33. van der Roer N, de Bruyne MC, Bakker FC, van Tulder MW, Boers M: Direct medical costs of traumatic thoracolumbar spine fractures. Acta Orthop 76:662-666, 2005

34. Wang H, Zhang Y, Xiang Q, Wang X, Li C, Xiong H, et al: Epidemiology of traumatic spinal fractures: experience from medical university-affiliated hospitals in Chongqing, China, 2001-2010. J Neurosurg Spine 17:459-468, 2012

35. Watts C, Smith H, Knoller N: Risks and cost-effectiveness of sublaminar wiring in posterior fusion of cervical spine trauma. Surg Neurol 40:457-460, 1993

36. Yousefzadeh Chabok S, Safaee M, Alizadeh A, Ahmadi Dafchahi M, Taghinnejadi O, Koochakinejad L:
Epidemiology of traumatic spinal injury: a descriptive study. Acta Med Iran 48:308-311, 2010

\section{Disclosures}

Dr. Furlan receives salary support from the Wings for Life Spinal Cord Research Foundation. Dr. Chan receives a post-doctoral fellowship that is funded by the Ontario Neurotrauma Foundation and the Rick Hansen Institute.

\section{Author Contributions}

Conception and design: all authors. Acquisition of data: all authors. Analysis and interpretation of data: all authors. Drafting the article: Furlan, Chan. Critically revising the article: all authors. Reviewed submitted version of manuscript: Furlan. Approved the final version of the manuscript on behalf of all authors: Furlan. Study supervision: Furlan, Craven.

\section{Correspondence}

Julio C. Furlan: Toronto Rehabilitation Institute, University Health Network, Toronto, ON, Canada. jcfurlan@gmail.com. 